\title{
Determinants of middle-school students asking parents for fruits and vegetables: a theory-based salient belief elicitation
}

\author{
Susan E Middlestadt, Alyssa M Lederer*, Nicole K Smith, Darleesa Doss, \\ Chia-Ling Hung, Laurel D Stevenson and Alyce D Fly \\ Department of Applied Health Science, Indiana University School of Public Health-Bloomington, \\ 1025 East 7th Street, HPER 116, Bloomington, IN 47405-7109, USA
}

Submitted 20 February 2012: Final revision received 9 July 2012: Accepted 31 August 2012: First published online 22 0ctober 2012

\begin{abstract}
Objective: Despite the benefits of fruit and vegetable intake, many young Americans do not consume them at adequate levels. The present study sought to determine the beliefs that children have about asking their parents to have fruits and vegetables available at home in order to better understand the role children may play in influencing their own fruit and vegetable consumption.

Design: An instrument utilizing the Reasoned Action Approach, with closedended questions on demographic and behavioural variables and open-ended questions eliciting the belief structure underlying asking parents to make fruits and vegetables available, was distributed. Thematic and frequency analyses were performed for open-ended questions. Statistical analyses were conducted to assess differences between children who had $v$. had not asked for fruits and vegetables.

Setting: Three middle schools in rural Indiana, USA.

Subjects: A sub-sample of sixty students aged $12-15$ years from a larger study of 344 students.

Results: Qualitative analysis identified benefits (i.e. make me healthier; make parents happy), disadvantages (i.e. will upset my parents) and strategies (i.e. asking when you are at the store) that could be used to improve fruit and vegetable intake. Findings also revealed that students who asked their parents for fruits and vegetables were significantly more likely to perform several healthy eating and physical activity behaviours.

Conclusions: Data suggest that young people's view of parental reactions is critical. While additional research is necessary, the findings support a role for children in shaping their own environment and suggest multilevel interventions that simultaneously address parents and children.
\end{abstract}

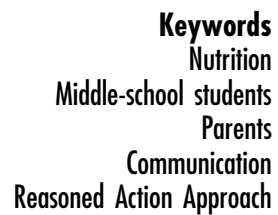

Establishing healthy eating habits early in life can improve both childhood and adult health. Childhood obesity has tripled in the last 30 years and continues to increase ${ }^{(1)}$. In $2008,19 \cdot 6 \%$ of children aged $6-11$ years and $18 \cdot 1 \%$ of adolescents aged 12-19 years were obese ${ }^{(2)}$. Obese young people are more likely than those of normal weight to have high cholesterol and high blood pressure $^{(3)}$, are at a greater risk of a host of physical and mental health concerns ${ }^{(4,5)}$, and are more likely to become overweight or obese adults who suffer from health consequences such as heart disease, type 2 diabetes and stroke ${ }^{(5)}$. Increased fruit and vegetable consumption is associated with weight reduction ${ }^{(6)}$ and other protective health effects among children, adolescents and adults ${ }^{(7)}$

Despite the importance of fruit and vegetable intake, young people are not consuming them at adequate levels $^{(8)}$ and there is evidence of a decline in consumption during the middle school years ${ }^{(9)}$. Given that the habits that adolescents adopt in their middle school years have been shown to correlate with their eating behaviours and outcomes later in life ${ }^{(10)}$, it becomes important to identify the beliefs underlying fruit and vegetable consumption to improve both current and future health status.

Research on the determinants of children and adolescents' fruit and vegetable consumption has increased markedly over the past decade ${ }^{(11)}$. Previous research has led to recommendations for improving fruit and vegetable intake in youth that focus on the family environment, including increased availability in the home and parental modelling ${ }^{(11-18)}$. Although parents are ultimately responsible for providing fruits and vegetables, and they have been the primary focus when examining the dyadic parent-child relationship ${ }^{(19)}$, children can play a role in influencing 
their parents to make fruits and vegetables available. Research on the child half of this interaction is beginning with studies on the measurement of proxy efficacy, which is children's confidence that they can get others to act in their interest ${ }^{(20-23)}$. Research on the factors underlying communication between children and parents about fruits and vegetables can help health professionals design interventions that improve availability in the home and therefore that increase consumption.

The present study sought to identify the top-of-themind beliefs held by middle-school students about asking their parents to have fruits and vegetables available at home. It is based on the Reasoned Action Approach (RAA), which has been used to explore decision making for a variety of behaviours ${ }^{(24)}$. The RAA states that behaviour is primarily determined by intention. Intention is, in turn, influenced by three global factors: (i) attitude towards the act; (ii) perceived norm; and (iii) perceived behavioural control or self-efficacy. Each of these global factors is based on underlying salient (top-of-the-mind) beliefs. Attitude is determined by beliefs about the salient consequences of engaging in the behaviour. Perceived norm is influenced by perceptions of what salient social referents think. Perceived behavioural control is based on beliefs about the salient circumstances that facilitate or hinder the behaviour. A critical step in the RAA is an elicitation to identify salient or top-of-the-mind consequences, referents and circumstances that form the belief structure of the behaviour ${ }^{(25)}$. The current study is a salient belief elicitation to identify the top-of-the-mind outcomes, referents and circumstances held by middleschool students about the behaviour of asking their parents to have fruits and vegetables for them to eat at home. To the authors' knowledge, the present study is the first one to use a theory-based approach to examine belief factors associated with dialogue between parents and their children about shaping the fruit and vegetable environment.

\section{Methods}

As part of a larger face-to-face semi-structured interview study with 344 students from three middle schools in rural Indiana from 2006 to 2008, an open-ended elicitation about asking parents to have fruit and vegetables available at home was conducted with sixty randomly selected students from the larger sample. The study was conducted according to the guidelines laid down in the Declaration of Helsinki and all procedures involving human subjects were approved by the Indiana University Institutional Review Board. Active parental consent and student assent were obtained through letters sent home for all participants. Information was collected using a computer-assisted personal interviewing system in a private school location.
The methods and analysis for the larger study are detailed more fully elsewhere ${ }^{(26)}$. Briefly, for the 344 students in the larger sample, the interview began with closed-ended items to assess self-reported behaviour related to a variety of eating and physical activity behaviours. Students were asked how many of the past $7 \mathrm{~d}$ they ate fruit, several green vegetables and several orange vegetables, as well as how many of the past five weekdays they engaged in three physical activity behaviours (see Table 1). Each student was asked elicitation questions for one eating and one physical activity behaviour selected at random. Demographic information was also ascertained. A calendar and pictures of fruits and vegetables were shown as prompts for both recall and to ensure accurate fruit and vegetable recognition.

For the sixty students who were queried about asking their parents to have fruits and vegetables available at home (henceforth referred to as 'asking'), the qualitative questions began with the following: 'As you know, health educators tell us to eat fruits and vegetables every day. Some people have told us that they did not eat these foods because they were not available. We want to know what you think and feel about asking your parents to have fruits and vegetables available for you to eat during the next three months. This could mean asking your parents to buy fruits and vegetables, to serve them at meals, to have them around for snacks, or to pack them in your lunch. There are no right or wrong answers. Just say what comes to your mind first'. Interviewers then asked six open-ended questions: two about consequences (i.e. "What are the advantages or good things that might happen if you ask your parents to have fruits and vegetables for you to eat at home during the next three months?' and 'What are the disadvantages or bad things that might happen...?'); two about social referents (i.e. 'Who, which people or groups, might approve or support you when you ask your parents to have fruits and vegetables for you to eat at home during the next three months?' and 'Who, which people or groups, might disapprove...?'); and two about circumstances (i.e. 'What might make it easier for you ask your parents to have fruits and vegetables for you to eat at home during the next three months?' and 'What might make it hard for you...?'). Interviewers probed after each question until participants exhausted their list of responses. Answers were recorded verbatim. The interview concluded with closed-ended questions on demographics and the food and physical activity environment.

The quantitative data analysis was conducted with the complete sample in order to achieve suitable statistical power given that these questions were asked of all participants. Past behaviour of asking was dichotomized; about half ( $n$ 186) reported asking at least once in the past week. Using the statistical software package PASW Statistics $18, \chi^{2}$ tests, $t$ tests and multivariate ANOVA determined whether asking was associated with gender, 
Table 1 Relationship between asking parents for fruits and vegetables to eat at home and selected demographic and behavioural variables among middle-school students aged 12-15 years, rural Indiana, USA, 2006-2008

\begin{tabular}{|c|c|c|c|c|c|c|c|}
\hline & \multicolumn{2}{|c|}{$\begin{array}{l}\text { Among all students } \\
\qquad(n 344)\end{array}$} & \multicolumn{2}{|c|}{$\begin{array}{l}\text { Among students } \\
\text { who asked } \\
\text { (n 186) }\end{array}$} & \multicolumn{2}{|c|}{$\begin{array}{l}\text { Among students } \\
\text { who did not ask } \\
\text { (n 158) }\end{array}$} & \multirow{2}{*}{$\begin{array}{c}\text { Inferential } \\
\text { statistic } \\
\left(\chi^{2}, t \text { or } F\right)\end{array}$} \\
\hline & $n$ & $\%$ & $n$ & $\%$ & $n$ & $\%$ & \\
\hline \multicolumn{7}{|l|}{ Column percentages } & \multirow{4}{*}{$3 \cdot 048^{(*)}$} \\
\hline Gender & & & & & & & \\
\hline Male & 161 & 47 & 79 & 42 & 82 & 52 & \\
\hline Female & 183 & $\begin{array}{r}53 \\
100\end{array}$ & 107 & $\begin{array}{r}58 \\
100\end{array}$ & 76 & $\begin{array}{r}48 \\
100\end{array}$ & \\
\hline Grade & & & & & & & \multirow{3}{*}{0.02} \\
\hline 7 th grade & 188 & 55 & 101 & 54 & 87 & 55 & \\
\hline 8th grade & 156 & $\begin{array}{r}45 \\
100\end{array}$ & 85 & $\begin{array}{r}45 \\
100\end{array}$ & 71 & $\begin{array}{r}45 \\
100\end{array}$ & \\
\hline Means & & & & & & & $t$ \\
\hline No. of adults in household & \multicolumn{2}{|c|}{$2 \cdot 16$} & \multicolumn{2}{|c|}{$2 \cdot 09$} & \multicolumn{2}{|c|}{$2 \cdot 24$} & $1 \cdot 85^{(*)}$ \\
\hline No. of children in household & \multirow{2}{*}{\multicolumn{2}{|c|}{$1 \cdot 45$}} & \multicolumn{2}{|c|}{$1 \cdot 49$} & \multirow{2}{*}{\multicolumn{2}{|c|}{$1 \cdot 39$}} & $-0 \cdot 75$ \\
\hline Eating behaviours & & & & & & & $F$ \\
\hline No. of days ate fruit & \multicolumn{2}{|c|}{3.03} & \multicolumn{2}{|c|}{$3 \cdot 33$} & \multicolumn{2}{|c|}{$2 \cdot 68$} & $16 \cdot 46^{\star * *}$ \\
\hline No. of days ate dark green lettuce, like romaine & \multicolumn{2}{|c|}{$1 \cdot 38$} & \multicolumn{2}{|c|}{$1 \cdot 42$} & \multicolumn{2}{|c|}{$1 \cdot 32$} & 0.37 \\
\hline No. of days ate broccoli & \multicolumn{2}{|c|}{$1 \cdot 13$} & \multicolumn{2}{|c|}{$1 \cdot 35$} & \multicolumn{2}{|c|}{$0 \cdot 87$} & $12 \cdot 89^{\star \star \star}$ \\
\hline No. of days ate spinach & \multicolumn{2}{|c|}{$0 \cdot 21$} & \multicolumn{2}{|c|}{$0 \cdot 26$} & \multicolumn{2}{|c|}{$0 \cdot 15$} & $3 \cdot 29^{(*)}$ \\
\hline No. of days ate kale & \multirow{2}{*}{\multicolumn{2}{|c|}{$\begin{array}{l}0.03 \\
0.12\end{array}$}} & \multirow{2}{*}{\multicolumn{2}{|c|}{$\begin{array}{l}0.04 \\
0.17\end{array}$}} & \multicolumn{2}{|c|}{$0 \cdot 01$} & $0 \cdot 81$ \\
\hline No. of days ate collard, turnip or mustard greens & & & & & & & $6 \cdot 79^{*}$ \\
\hline No. of days ate carrots & \multicolumn{2}{|c|}{1.67} & & & & & $2 \cdot 58$ \\
\hline No. of days ate sweet potatoes & & & & & & & $2 \cdot 54$ \\
\hline No. of days ate pumpkin & & & & & & & 0.22 \\
\hline No. of days ate winter squash & & & & & & & 0.73 \\
\hline No. of weekdays ate breakfast & & & & & & & $0 \cdot 91$ \\
\hline Physical activity behaviours & & & & & & & \\
\hline No. of weekdays walked after school & & & & & & & $5 \cdot 36^{\star}$ \\
\hline No. of weekdays played sports after school & & & & & & & $7 \cdot 59^{\star *}$ \\
\hline No. of weekdays played actively in house after school & & & & & & & $3 \cdot 42$ \\
\hline
\end{tabular}

${ }^{(\star)} P<0 \cdot 10,{ }^{\star} P<0.05,{ }^{* \star} P<0 \cdot 01,{ }^{* \star *} P<0.001$.

grade, number of adults and children in the household, and several eating and physical activity behaviours. Table 1 compares students who asked at least once weekly with those who did not ask at all during the week.

For the qualitative data asked of the sub-sample, a content analysis was conducted to create categories of similar responses. Responses were grouped into categories of consequences (advantages and disadvantages), referents (people who approve and disapprove) and circumstances (what makes it easy and hard). A team of coders experienced in RAA and in nutrition reviewed each category. Rare disagreements were discussed until consensus was reached, which it was in all cases. Additionally, as part of the larger study, the coding of a subset of elicitation responses was assessed for inter-rater reliability. There was a high reliability coefficient for each category of responses, ranging from $\kappa=0.877$ to $\kappa=0.956$. This process is detailed elsewhere ${ }^{(26)}$. The data in the form of mentioned/not mentioned variables for each of the thematic categories were merged with the closed-ended data. Results of an initial frequency analysis were discussed by the team and categories were combined. Tables 2-4 present the number and percentage of participants who mentioned each of the final categories of beliefs.

\section{Results}

Participants ranged in age from 12 to 15 years (mean 13 (SD $0 \cdot 1$ ) years). About half were in 7 th grade and about half in 8 th grade; about half were female. Nearly all described themselves as white (97\%). The schools were located in rural Indiana and reported about one-third of students eligible for free and reduced-price lunches.

\section{Behaviours related to asking}

As shown in Table 1, over half (54\%) of the students reported asking their parents to provide fruits and vegetables one or more times in the $7 \mathrm{~d}$ before the survey. These individuals were considered 'students who asked'. Univariate tests revealed that students who asked for fruits and vegetables at least once in the past week had a significantly higher mean number of days of eating fruits and some vegetables and engaging in most physical activities compared with those who did not ask. Multivariate tests indicated that students who asked to have fruits and vegetables to eat at home reported practising healthy behaviours more frequently for both eating $(F(10,331)=2 \cdot 95, P<0 \cdot 01$, Wilk's $\lambda=0.911)$ and physical activity $(F(2,339)=4 \cdot 65, P<0 \cdot 01$, Wilk's $\lambda=0 \cdot 961)$. 


\section{Salient consequences underlying attitude component}

As shown in Table 2, several health consequences, both positive and negative, were at the top of the students' minds. The most frequently mentioned advantage (48\%) was 'will make me healthier'. In addition, 18\% said asking 'will help me eat healthy' and 20\% said that asking 'will help me eat less unhealthy food'. Several students

Table 2 Salient consequences of asking parents to have fruits vegetables to eat at home for the next three months among middleschool students aged 12-15 years, rural Indiana, USA, 2006-2008

\begin{tabular}{lcc}
\hline \multicolumn{4}{c}{ Advantages } \\
\hline \multicolumn{3}{c}{ Asking my parents to have fruits and vegetables available... } \\
\hline$n 60$ & Count & $\%$ \\
\hline Will make me healthier & 29 & 48 \\
My parents will buy them & 15 & 25 \\
Will help me eat less unhealthy food & 12 & 20 \\
Will help me eat healthy & 11 & 18 \\
Will give me energy & 11 & 18 \\
Will make me more active & 8 & 13 \\
Will help me eat things that I like & 6 & 10 \\
Will help me lose weight & 5 & 8 \\
Will make my parents happy & 4 & 7 \\
\hline
\end{tabular}

\begin{tabular}{lcc}
\hline \multicolumn{3}{c}{ Disadvantages } \\
\hline \multicolumn{3}{c}{ Asking my parents to have fruits and vegetables available... } \\
\hline$n 60$ & Count & $\%$ \\
\hline Will upset my parents & 17 & 28 \\
Will make me eat things I don't like & 15 & 25 \\
Will make me sick & 7 & 12 \\
Wanting to eat other things & 6 & 10 \\
Will make me gain weight & 4 & 7 \\
None & 24 & 40 \\
\hline
\end{tabular}

Percentages sum to more than $100 \%$ since participants could list multiple answers. identified unhealthy consequences. Some students (12\%) mentioned that asking 'will make me sick', with one stating, 'There might be mould on the fruit and you could get sick from that'. Another, referring to a recent food-borne illness outbreak, stated: 'If your parents get spinach, it might have the disease in it'. Some students were concerned about the effect of asking on their weight (i.e. 'will make me gain weight' (7\%) and 'will help me lose weight' (8\%)).

Students readily recognized the role that their parents play and were concerned about the reaction of their parents to the request for fruits and vegetables. Many (25\%) noted that asking will result in 'parents buying fruits and vegetables' and a few (7\%) mentioned that it 'will make my parents happy'. Several were concerned that asking 'will upset my parents' (28\%). Statements such as 'She might say no; I get a little nervous' show that fear of a negative response may inhibit asking.

Many students thought about the effect of asking on their ability to enjoy what they eat. While only $10 \%$ admitted that asking 'will help me eat things that I like', a quarter noted that asking 'will make me eat things I don't like' and $10 \%$ stated that they 'want to eat other things'. In one student's words: 'I like junk food. But if I asked my parents to have fruits and vegetables in the house, they might go overboard and only have fruits and vegetables to eat'. Finally, $40 \%$ could think of no disadvantages of asking.

\section{Salient circumstances underlying control component}

Table 3 presents the salient circumstances that emerged when students were asked what makes it easier and harder to ask parents to have fruits and vegetables to eat at home. First, and consistent with the concern about parental reaction discussed above, half indicated that a

Table 3 Salient circumstances of asking parents to have fruits and vegetables to eat at home for the next three months among middleschool students aged 12-15 years, rural Indiana, USA, 2006-2008

\begin{tabular}{|c|c|c|c|c|c|}
\hline \multicolumn{6}{|c|}{ Salient circumstances } \\
\hline \multicolumn{3}{|l|}{ Facilitators } & \multicolumn{3}{|c|}{ Barriers } \\
\hline \multicolumn{3}{|c|}{$\begin{array}{l}\text {...makes it easier to ask my parents to make fruits and vegetables } \\
\text { available }\end{array}$} & \multicolumn{3}{|c|}{$\begin{array}{c}\text {...makes it harder to ask my parents to make fruits and } \\
\text { vegetables available }\end{array}$} \\
\hline \multirow[t]{2}{*}{$n 60$} & Count & $\%$ & $n 60$ & Count & $\%$ \\
\hline & & & Worried parents will say no & 30 & 50 \\
\hline Having lower cost & 7 & 12 & Having higher cost & 18 & 30 \\
\hline Parents having the time & 2 & 3 & Parents not having the time & 12 & 20 \\
\hline Parents like them & 2 & 3 & Parents don't like them & 6 & 10 \\
\hline Telling them it will make you healthy & 10 & 17 & & & \\
\hline Asking when you are at the store & 9 & 15 & & & \\
\hline Having someone to do it with & 7 & 12 & & & \\
\hline Eating them so you need more & 4 & 7 & & & \\
\hline Just ask them & 12 & 20 & & & \\
\hline None/don't know & 8 & 13 & None/don't know & 24 & 40 \\
\hline
\end{tabular}

Percentages sum to more than $100 \%$ since participants could list multiple answers. 
Table 4 Salient referents of asking parents to have fruits and vegetables to eat at home for the next three months among middle-school students aged 12-15 years, rural Indiana, USA, 2006-2008

\begin{tabular}{|c|c|c|c|c|c|}
\hline \multicolumn{6}{|c|}{ Salient referents } \\
\hline \multicolumn{3}{|c|}{ Approving referents } & \multicolumn{3}{|c|}{ Disapproving referents } \\
\hline \multicolumn{3}{|c|}{$\begin{array}{c}\text {... approves of me asking my parents to have fruits and } \\
\text { vegetables to eat at home }\end{array}$} & \multicolumn{3}{|c|}{$\begin{array}{c}\text {... disapproves of me asking my parents to have fruits ano } \\
\text { vegetables to eat at home }\end{array}$} \\
\hline$n 60$ & Count & $\%$ & $n 60$ & Count & $\%$ \\
\hline Parental figures & 58 & 97 & Parental figures & 7 & 12 \\
\hline Parents & 18 & 30 & Parents & 1 & 2 \\
\hline Mom & 12 & 20 & & & \\
\hline Dad & 11 & 18 & Dad & 4 & 7 \\
\hline Grandma & 10 & 17 & Grandma & 1 & 2 \\
\hline Grandparent & 4 & 7 & & & \\
\hline Grandpa & 3 & 5 & Grandpa & 1 & 2 \\
\hline Siblings & 14 & 23 & Siblings & 10 & 17 \\
\hline Friends & 10 & 17 & Friends & 7 & 12 \\
\hline Teachers & 14 & 23 & & & \\
\hline \multirow[t]{2}{*}{ Health professionals } & 8 & 5 & & & \\
\hline & & & Nobody/none & 36 & 60 \\
\hline
\end{tabular}

Percentages sum to more than $100 \%$ since participants could list multiple answers.

barrier to asking for fruits and vegetables is that they were 'worried my parents will say no'. Parental enjoyment (i.e. 'parents don't like them' (10\%) and 'parents like them' (3\%)) influenced the ease with which they could ask.

Two perceived circumstances revealed that students can take the perspective of their parents. Twelve per cent mentioned 'having a lower cost' would make asking easier and 30\% stated that 'having higher cost' would make it harder. For example, one student said: 'My parents might be frustrated about it if they couldn't buy them because they didn't have enough money'. Similarly, while only $3 \%$ of students reported that 'parents having the time' made asking easier, $20 \%$ stated that 'parents not having the time' made asking harder. In one student's words: 'They might have to go out of their way to get them'.

Finally, asking students what might make asking easier elicited a number of strategies to facilitate asking. Seventeen per cent offered that 'telling them it will make you healthy' would make it easier to ask their parents. One student said: 'Persuade them by telling them that you'd be healthier'. Other students suggested 'asking when you are at the store' (15\%). The response 'If we are at the store together and I saw it' illustrates the value of timing and convenience. A few students recommended 'having someone to do it with' (12\%), with responses like 'Tell my sister to do it. She's braver than I am'. Other students offered the strategy of 'just asking them' (20\%).

\section{Salient referents underlying normative component}

As seen in Table 4, the referents mentioned as approving or disapproving included family members, friends, people at school, and health professionals. In general, older adults (i.e. 'parents', 'grandparents' and 'teachers') were perceived to support the behaviour of asking for fruits and vegetables. While the majority of students (60\%) stated that no one would disapprove of their asking for fruits and vegetables, people similar in age, such as 'friends' (12\%) and 'siblings' (23\%), were elicited as salient referents who would disapprove.

\section{Discussion}

The present study applied the RAA to identify the behavioural, normative and control beliefs underlying middle-school students' decision to ask their parents to have fruits and vegetables for them to eat at home. We believe that this research is particularly useful given Baranowski ${ }^{(19)}$ and others' call for innovative theorybased approaches appropriate for youth that determine mediating variables related to dietary intake to inform intervention design. The present study was novel in that it used a theory-based approach to investigate the less examined role of the child in the parent-child dyadic model in an effort to explore a behaviour associated with home availability of fruits and vegetables, a leading determinant of fruit and vegetable consumption among children $^{(11-18)}$.

Over half of the participants asked their parents to make fruits and vegetables available at least once in the past week. It is encouraging that asking was found to be a behaviour that young people currently engage in and provides reason to believe that more young people could ask if equipped with skills that facilitate improved communication with their parents or caregivers. This is particularly important given that many students indicated that asking would lead to parents buying fruits and vegetables. Furthermore, quantitative analyses revealed that past behaviour of asking for fruits and vegetables was significantly associated with the behaviours of eating 
more fruit and several green vegetables as well as with walking and playing sports after school. While the causal direction of these findings is unknown, they support the potential role of asking parents to make fruits and vegetables available in increasing fruit and vegetable consumption and the value of understanding the beliefs underlying the behaviour of asking.

These middle-school students perceived a number of salient consequences, referents and circumstances of asking that can be used to improve fruit and vegetable intake. Notably, the vast majority of students could think of at least one parental figure who would support their asking for fruits and vegetables. Parents and other salient referents listed by the students were consistent with those for other eating and physical activity behaviours ${ }^{(26)}$. While the majority of students thought no one would disapprove of their asking for fruits and vegetables, it is worth noting that some students (12\%) believed a parental figure would disapprove.

In addition, the beliefs elicited reveal a number of examples related to students' complex reasoning. Students believed that one advantage of asking parents to have fruits and vegetables available was that parents would buy them. Students also mentioned a number of other perceived advantages related to eating fruits and vegetables, meaning that students likely believed that by asking their parents to buy fruits and vegetables, parents would do so and, in turn, students would eat them and experience a number of health benefits (make me healthier, help me eat less unhealthy food, give me energy, etc.). However, although students expressed that an advantage of asking would be that their parents would buy fruits and vegetables, some students also expressed a belief that asking would lead them to have to eat foods they didn't like. Past research has shown that children and adolescents may have a greater preference for fruits ${ }^{(12,27)}$ and that preference is an important determinant of consumption $^{(11,12,16-18,27)}$. Therefore, interventions that alter food preferences may be effective at increasing fruit and vegetable consumption via asking behaviour. Parental modelling and continual introduction and exposure to foods adolescents perceive as distasteful have also been shown to increase consumption ${ }^{(12)}$.

These findings also suggest that students were aware of time and monetary constraints influencing their parents and concerns about these realistic issues may impede asking. Additionally, students were cognizant of potential reactions to their request: some thought asking would make their parents happy and several believed that parents approved of asking, yet many were concerned their parents would say no, or even more that asking would cause their parents to get upset. Although from these data it is not possible to determine what the parents actually believed, these potential negative reactions are worthy of future study. Lastly, and perhaps as a result of the potential reaction of their parents, these students provided strategies to help young people like themselves ask. These strategies ranged from persuasive communication approaches (i.e. telling them it will make you healthy), to timing (i.e. asking them when you are at the store), to having social support (i.e. having someone to do it with) and finally to just doing it.

These findings support the role of parent-child communication in improving eating and provide insight into factors that health professionals can address in related interventions designed to improve the behaviour of asking. Interventions should focus on the parent-child dyad and empower young people to ask their parents for fruits and vegetables while ensuring parents become aware of some children's real or perceived fear of doing so. The advantages students provided should be highlighted and approving referents should be suggested for support. Strategies for asking given by students themselves should be recommended.

The primary limitation of the present study is its generalizability. Data were collected from a small, convenience sample of primarily white students from rural Indiana. While a small sample size is appropriate for a salient belief elicitation ${ }^{(24)}$, findings might be different with other populations. The study does, however, lead us to recommend additional research on the child's role. A larger follow-up study that uses closed-ended items based on these qualitative results and that determines which beliefs are more strongly associated with intention is needed to confirm decisions about which specific belief factors to target with future interventions. Research should also explore the parental perspective on being asked to provide fruits and vegetables for their children in comparison to these findings.

Additionally, the present study examined the behaviour of asking parents to provide fruits and vegetables, and we were unable to differentiate between asking for fruits and asking for vegetables. Future research is needed to explore possible differences in determinants of asking for fruits from asking for vegetables given the evidence that consumption may be partially determined by food preference and in some cases fruit consumption and vegetable consumption have been found to be independent behaviours ${ }^{(21)}$.

These findings provide more context for Dzewaltowski and Geller's recent extension of Bandura's conceptualization of proxy efficacy in relation to fruit and vegetable consumption in youth. Proxy efficacy is a special type of self-efficacy relevant when individuals rely on others to act on their behalf ${ }^{(28)}$ as young people must do with asking their parents to make fruits and vegetables available to them. Dzewaltowski and Geller have found that proxy efficacy is related to but independent of self-efficacy and that valid and reliable instrumentation exists to measure the proxy efficacy construct ${ }^{(20,21)}$. In another study they found that male youths and youths with lower socio-economic status were less likely to have proxy 
efficacy than their female and higher socio-economic status counterparts ${ }^{(22)}$. The salient beliefs revealed in our study may provide insight into factors associated with increased or decreased proxy efficacy. Thus, additional research should examine the connection of proxy efficacy to the behavioural, normative and control beliefs about asking as outlined by the RAA. Interventions that endeavour to improve proxy efficacy should be explored. Dzewaltowski and colleagues have begun to do so in respect to the school environment ${ }^{(23)}$. Additional research is needed to extend this work to the home environment and to identify what strategies may be effective in promoting middle-school students' proxy efficacy related to fruit and vegetable consumption. The salient beliefs about asking identified in the present paper may provide one mechanism for doing so.

\section{Conclusions}

The present study used a theory-based method to reveal factors that can encourage middle-school students to ask their parents to have fruits and vegetables for them to eat at home and thus to shape their environment and to improve their eating. The findings provide young people's perspectives in their own words and demonstrate the need for interventions that can facilitate dialogue between parents and their children. The findings suggest short-term benefits that can be highlighted (i.e. eat things you like, get energy, get more active, get healthy, make parents happy) and provide strategies to encourage asking. Finally, the findings reinforce the pivotal role of parents as perceived by young people and suggest that multilevel interventions should address both parent and child roles. Middle-school students can and want to shape their own environments; parents and health professionals must provide the opportunity for them to do so in a healthy manner.

\section{Acknowledgements}

Sources of funding: Parts of the research were supported by Indiana University through a Special State Funds Award (2345709). Conflicts of interest: No conflicts of interest exist for any of the authors. Autbors' contributions: S.E.M. was the principal investigator for the study and took a primary role in conceptualizing, overseeing and editing the manuscript. A.M.L., N.K.S. and D.D. played a key role in the qualitative analysis and writing of the manuscript. C.-L.H. was primarily responsible for the quantitative statistical analysis. L.D.S. and A.D.F. were integral to the original study and made important modifications to the manuscript. Acknowledgements: The authors wish to acknowledge the faculty and students who helped with the various stages of the Eating Better and Moving More project, as well as the individuals and the organizations who participated.

\section{References}

1. Ogden C, Carroll M (2010) Prevalence of Obesity Among Children and Adolescents: United States, Trends 1963-1965 through 2007-2008. Atlanta, GA: Centers for Disease Control and Prevention, National Center for Health Statistics; available at http://www.cdc.gov/nchs/data/hestat/obesity_ child_07_08/obesity_child_07_08.htm

2. Ogden CL, Carroll MD, Curtin LR et al. (2010) Prevalence of high body mass index in US children and adolescents, 2007-2008. JAMA 303, 242-249.

3. Freedman DS, Zuguo M, Srinivasan SR et al. (2007) Cardiovascular risk factors and excess adiposity among overweight children and adolescents: the Bogalusa Heart Study. J Pediatr 150, 12-17.

4. Daniels SR, Arnett DK, Eckel RH et al. (2005) Overweight in children and adolescents: pathophysiology, consequences, prevention, and treatment. Circulation 111, 1999-2002.

5. US Department of Health and Human Services (2001) The Surgeon General's Call to Action to Prevent and Decrease Overweight and Obesity. Rockville, MD: US Department of Health and Human Services, Public Health Service, Office of the Surgeon General.

6. Rolls BJ, Ello-Martin JA \& Tohill BC (2004) What can intervention studies tell us about the relationship between fruit and vegetable consumption and weight management? Nutr Rev 62, 1-17.

7. World Health Organization (2002) The World Health Report. Reducing Risks, Promoting Healthy Life. Geneva: WHO; available at http://www.who.int/whr/2002/en/whr02_en.pdf

8. Kim SA, Grimm KA, Harris DM et al. (2011) Fruit and vegetable consumption among high school students United States, 2010. MMWR Morb Mortal Wkly Rep 60, 1583-1586.

9. Lien N, Lytle LA \& Klepp KI (2001) Stability in consumption of fruit, vegetables, and sugary foods in a cohort from age 14 to age 21. Prev Med 33, 217-226.

10. Mikkila V, Rasanen L, Raiakari OT et al. (2004) Longitudinal changes in diet from childhood into adulthood with respect to risk of cardiovascular diseases: the Cardiovascular Risk in Youth Finns Study. Eur J Clin Nutr 58, 1038-1045.

11. Rasmussen M, Krølner R, Klepp KI et al. (2006) Determinants of fruit and vegetable consumption among children and adolescents: a review of the literature. Part I: Quantitative studies. Int J Behav Nutr Phys Act 3, 22.

12. Blanchette L \& Brug L (2005) Determinants of fruit and vegetable consumption among 6-12 year old children and effective interventions to increase consumption. I Hum Nutr Diet 18, 431-443.

13. Pearson N, Biddle SJH \& Gorely T (2008) Family correlates of fruit and vegetable consumption in children and adolescents: a systematic review. Public Health Nutr 12, 267-283.

14. Hanson NI, Neumark-Sztainer D, Eisenberg ME et al. (2005) Associations between parental report of home food environment and adolescent intakes of fruit, vegetables and dairy foods. Public Health Nutr 8, 77-85.

15. Gellar LA, Schrader K \& Nansel TR (2007) Healthy eating practices: perceptions, facilitators, and barriers among youth with diabetes. Diabetes Educ 33, 671-679.

16. Geller KL \& Dzewaltowski DA (2009) Longitudinal and cross sectional influences on youth fruit and vegetable consumption. Nutr Rev 67, 65-76.

17. Cullen KW, Baranowski T \& Owens E (2003) Availability, accessibility, and preferences for fruit, $100 \%$ fruit juice, and vegetables influence children's dietary behavior. Health Educ Behav 30, 615-626.

18. Neumark-Sztainer D, Wall M, Perry C et al. (2003) Correlates of fruit and vegetable intake among adolescents findings from Project EAT. Prev Med 37, 198-208. 
19. Baranowski T (2006) Advances in basic behavioral research will make the most important contributions to effective dietary change programs at this time. J Am Diet Assoc 106, 808-811.

20. Geller KS \& Dzewaltowski DA (2010) Examining elementary school-aged children's self-efficacy and proxy efficacy for fruit and vegetable consumption. Health Educ Behav 37, 465-478.

21. Geller KS, Dzewaltowski DA, Rosendranz RR et al. (2009) Measuring children's self-efficacy and proxy efficacy related to fruit and vegetable consumption. $J$ Sch Health 79, 51-57.

22. Geller KS \& Dzewaltowski DA (2010) Youth proxy efficacy for fruit and vegetable availability varies by gender and socio-economic status. Public Health Nutr 13, 843-851.

23. Dzewaltowski DA, Estabrooks PA, Welk G et al. (2009) Healthy youth places: a randomized controlled trial to determine the effectiveness of facilitating adult and youth leaders to promote physical activity and fruit and vegetable consumption in middle schools. Health Educ Behav 36, 583-600.

24. Fishbein M \& Ajzen I (2010) Predicting and Changing Behavior. New York: Psychology Press.

25. Middlestadt SE, Bhattcharyya K, Rosenbaum J et al. (1996) The use of theory-based semi-structured elicitation questionnaires: formative research for CDC's Prevention Marketing Initiative. Public Health Rep 111, Suppl. 1, 18-27.

26. Middlestadt SE (2012) Reasons for eating better and moving more: lessons learned about the salient belief elicitation. Ann Am Acad Polit Soc Sci 640, 81-100.

27. Domel Baxter S \& Thompson WO (2002) Fourth-grade children's consumption of fruit and vegetable items available as part of school lunches is closely related to preferences. J Nutr Educ Behav 34, 166-171.

28. Bandura A (2001) Social cognitive theory: an agentic perspective. Annu Rev Psychol 52, 1-26. 